\title{
ELECTROCARDIOGRAPHIC CHANGES WITH STANDARD DOSE OF MEGLUMINE ANTIMONIATE THERAPY IN CUTANEOUS LEISHMANIASIS
}

\author{
Moizza Tahir, Uzma Bashir*, Najia Ahmed**, Jauhar Mumtaz ${ }^{* * *}$ \\ Combined Military Hospital Multan/National University of Medical Sciences (NUMS) Pakistan, ${ }^{*}$ Combined Military Hospital Quetta/National University of \\ Medical Sciences (NUMS) Pakistan, **Pakistan Naval Ship Shifa Hospital, Karachi Pakistan, ***Ali Medical Centre, Islamabad Pakistan
}

\begin{abstract}
Objective: To identify electrocardiographic changes associated with parenteral meglumine antimoniate and to estimate frequency of these changes.

Study Design: Prospective observational study.

Place and Duration of Study: Dermatology department, Combined Military Hospital Quetta and Multan, from Apr 2018 to Feb 2019.

Methodology: Total of 87 patients was recruited by consecutive sampling technique. Cases of Leishmaniasis were confirmed by Leishmania donovani bodies in smear or skin biopsy. Base line electrocardiograph was done and then repeated weekly. All patients were given $15 \mathrm{mg} / \mathrm{kg}$ body weight intramuscular meglumine antimoniate (Glucantime). Any change in electrocardiograph was documented. Follow up electrocardiograph was repeated two weeks after hospital discharge. Data was analyzed using SPSS-20.

Results: Changes in electrocardiograph appeared between 7-27 days mean $16 \mathrm{SD} \pm 4.58$. T-wave inversion was recorded in 41 $(47.12 \%)$, ST elevation in $1(1.14 \%)$, prolonged QT interval in $1(1.14 \%)$. Meglumine antimoniate therapy was discontinued after ECG change for $5 \pm$ SD 3 days of therapy. Follow up electrocardiograph two weeks after hospital discharge was normal. Conclusion: Early repolarization defects of T wave inversion and ST segment deviation were found with standard doses of meglumine antimoniate therapy.
\end{abstract}

Keywords: Cutaneous leishmaniasis, Electrocardiographic adverse effects, Meglumine antimoniate.

This is an Open Access article distributed under the terms of the Creative Commons Attribution License (https://creativecommons.org/licenses/by-nc/4.0/, which permits unrestricted use, distribution, and reproduction in any medium, provided the original work is properly cited.

\section{INTRODUCTION}

Cutaneous Leishmaniasis (CL) is endemic in Pakistan. Upto 2 million cases are reported annually worldwide. It has not only increased at a significant rate but also involved a wider geographic distribution. In Balochistan areas affected are Uthal, Quetta and Ormara $^{1}$. CL is found in metropolitan Multan city and outbreaks of CL were reported in 14 of the 68 Union Councils of Multan2. Disease is considered as major health burden. CL is a vector-borne infection caused by flagellated parasitic protozoans in the genus Leishmania. Female sand flies of the genera Phlebotomus or Lutzomyia transmit infective promastigotes. Clinical spectrum varies from classical oriental sore to unusual presentations ${ }^{3,4}$. The unusual presentations included acute paronychial, chancriform, annular, palmoplantar, zosteriform and erysipeloid forms. The reason for clinical pleomorphism of CL is not clear but immunosuppression may have a role.

The predominant parasite in lowland areas of Pakistan was L. major (97.9\%), while high land areas L. tropica $(76.2 \%)$ was more common. Systemic treat-

Correspondence: Dr Moizza Tahir, Classified Dermatologist, Combined Military Hospital, Multan Pakistan

Received: 29 Mar 2020; revised received: 06 Aug 2020; accepted: 11 Aug 2020 ments are not equally effective against all species of Leishmania, and healing rates differ among the same species geographically. Host cell-mediated immunity is important to control infection. Therefore, CL treatment needs to be individualized to the patient, Leishmania species, and the geographic region where infection was acquired 5 .

Pentavalent antimonial compounds are considered as effective treatment for CL as first line agents ${ }^{6}$. Miltefosine is the only oral anti-leishmanial drug widely practiced but decrease in its susceptibility has been documented. Manzamines are new unique group of $\beta$ carboline alkaloids isolated from marine sponges and showed potent anti-leishmanial activity ${ }^{7}$. Indications for systemic treatment of cutaneous leishmaniasis are lesion size $>4 \mathrm{~cm}$, number of active lesion $>3$, lesion location on body areas potentially disfiguring or disabling from scar formation (e.g., face, fingers, toes, ears, large joints), lesion duration $>6$ months, associated medical conditions e.g. diabetes mellitus, pregnancy, immunosuppression (including HIV), and chronic comorbidities (e.g., congestive heart failure, moderate to severe liver disease, renal dysfunction), age $>55$ years and local spread or disseminated infection ${ }^{8}$. Meglumine antimonite $(5 \mathrm{~mL})$ contains about $8.5 \%$ antimony $(85 \mathrm{mg} 5 / \mathrm{mL})$. This drug is administered paren- 
tally at a dosage of $15-20 \mathrm{mg} / \mathrm{kg} /$ day, until clinical cure of the lesions ${ }^{9}$.

Cardiotoxicity of high-dose pentavalent antimony is well known, though low-dose short-term meglumine has been considered to be safe and relatively free from significant cardiac effects. Cardiotoxic effects of pentavalent antimony compounds include ST segment depression, QT interval prolongation, torsadepointes arrhythmias and sudden cardiac death. These changes are estimated in $10 \%$ of population in late stages of treatment ${ }^{10}$. There are other changes described in published literature but frequency of these changes in population of Pakistan has not been described earlier with standard dose of meglumine antimoniate. The aim of present study was to identify ECG changes associated with IM meglumine antimoniate $(15 \mathrm{mg} / \mathrm{kg} /$ day $)$ recommended for the treatment of the CL and to estimate the frequency of these changes. The study would ensure safe practice.

\section{METHODOLOGY}

This study was conducted at tertiary care hospital of Quetta and Multan after Institutional Ethical Review Board (IERB) approval from April 2018 to February 2019. Ejaz et al, in their study of cutaneous Leishmaniasis in Balochistan described estimated prevalence of cutaneous Leishmaniasis as $2.7 \%$ in the northwestern population of the Pakistan ${ }^{11}$. Sample size of 41 or more with confidence interval of $95 \%$ and margin of error $5 \%$ was calculated with WHO sample size calculator. Total of 87 patients were enrolled by consecutive sampling technique after informed consent. All patients were confirmed cases of CL. Diagnosis was confirmed by positive LD smear or histopathology findings consistent with cutaneous Leishmaniasis. Patients with plaque $>4 \mathrm{~cm}$, lesion number $>3$, non-healing sore $>4$ months, lesion on face, large joints, hand and toes were included in the study. Patients with known hypersensitivity to meglumine antimoniate, cardiac disease, chronic medical illness, and children, pregnant and nursing mothers were excluded. Routine blood examination, urine analysis, hepatic and renal function tests, serum amylase and ECG were done in each case before starting treatment. All patients were hospitalized and treated with intramuscular intragluteal Meglumine antimoniate (Glucantime-sanofi Aventis) in a dose of $15 \mathrm{mg} / \mathrm{kg} / \mathrm{bwt}$ per day. ECG was done before, during (weekly) and at follow up visit two weeks after hospital discharge. ECG analysis was done by dermatologists who were blinded to therapy status. Collected data was analysed using SPSS-20 software. Descriptive statistics were used for age, duration of treatment, ECG changes. Frequency of ECG changes was recorded. Dose and day when ECG change appeared was analyzed by paired sample t-test and $p$-value of $<0.05$ was considered as significant.

\section{RESULTS}

A total of 87 male patients were enrolled in this study. Age ranged from 21-50 years with mean of $30.12 \pm$ SD 2.1. Number of lesions range from 1-9; mean $3.03 \pm$ SD 1.072. Pretreatment ECG of all patients was normal. Meglumine antimoniate was administered intramuscular (IM) intragluteal after test dose (ATD) as $15 \mathrm{mg} / \mathrm{kg} /$ day. All patients received 28 days treatment with Meglumine antimoniate.

These changes were observed from 7-27 days, mean $16 \pm$ SD 4.58. ECG change were unique to each patient, MA therapy was discontinued after ECG change for $5 \pm$ SD 3 days. Treatment was restarted as ECG returned to normal. All patients remained clinically asymptomatic and completed 28 days of treatment. Follow up ECG two weeks after completion of treatment was normal. Dose of meglumine antimoniate was standardized to $15 \mathrm{mg} / \mathrm{kg}$ for all patients. However 72 $(82.7 \%)$ received $15 \mathrm{mg} / \mathrm{kg}$ of meglumine antimoniate therapy whereas $15(17.24 \%)$ patients were switched to meglumine antimoniate $10 \mathrm{mg} / \mathrm{kg}$ due to systemic upsets as nausea, myalgia, fever. Five (5.74\%) patients receiving $10 \mathrm{mg} / \mathrm{kg}$ of MA developed ECG changes. Dose of MA mean $13.05 \pm$ SD 2.965 and day mean $16 \pm$ SD 4.53 when ECG changes appeared. There was no significant difference $p$-value $<0.153$.

Table-I: Frequency of electrocardiograph change.

\begin{tabular}{l|c}
\hline T- wave inversion & $\mathbf{n ~ ( \% )}$ \\
\hline ST Elevation & $41(47.12)$ \\
\hline QT interval Prolongation & $1(1.14)$ \\
\hline Total Patients with ECG Change & $1(1.14)$ \\
\hline \multicolumn{2}{l}{ Table-II: Frequency of t-wave changes in leads. } \\
\hline T Wave Changes in Leads & $\mathbf{n}(\%)$ \\
\hline III & $8(19.5)$ \\
\hline III, aVf & $16(39.02)$ \\
\hline II,III,aVf, V2-V6 & $3(7.3)$ \\
\hline V2-V6 & $2(4.8)$ \\
\hline II,III,aVf, V4-V6 & $7(17.07)$ \\
\hline
\end{tabular}

\section{DISCUSSION}

Cutaneous leishmaniais (CL) is a major public health problem. The WHO considers it a neglected and an emerging uncontrolled disease. The management of $\mathrm{CL}$ is based on regional evidence based experience ${ }^{12}$. 
There are concerns about cost, availability, poor compliance, and systemic toxicity of pentavalent antimonial compounds. Males are more commonly affected, this finding is in accordance with a study conducted by Moein et al, in the city of Kehsan at Iran they reported $58 \%$ of males were affected by disease ${ }^{13}$. Disease is more frequent in males due to risks of exposure but also due to gender related difference in host response to infection ${ }^{14}$.

T-wave changes in particular T-wave inversion were the commonest finding in our patients. Kevric et al, described reversible T-wave changes in ECG and cardio toxicity as common reported adverse effect of meglumine antimoniate therapy. ECG was recommended before initiating treatment and then biweekly during therapy ${ }^{15}$. However in a study conducted in Syria, treatment with $60 \mathrm{mg} / \mathrm{kg} /$ day (MA) for 21 days induced ECG changes such as prolong QT interval was observed. They emphasized identifying potential factors that may increase the risk of QTc prolongation and arrhythmias. However it was concluded that systemic (MA) can safely be used with adequate monitoring. It doesn't need treatment interruption ${ }^{16}$. Sadeghian in a prospective study of 131 patients at Iran found pronlged QT interval $(19 \%)$ as commonest finding, and ECG changes reversed after discontinuation of therapy ${ }^{17}$. Viguer MTC et al, reported that MA is well tolerated in Spain, nevertheless it frequently altered ventricular repolarization and lead to sudden cardiac death, possibly due to ventricular arrhythmias. They reported a case of torsade pointes during treatment with MA, with coexisting hypokalemia due to acute transitory tubulopathy ${ }^{18}$.

ST segment deviations and T-wave inversions are considered as early repolarization ventricular defects ${ }^{19}$. Although MA remains first line of drug by the WHO for the treatment of all types of Leishmaniasis. Its mechanisms of action and toxicity, including its genotoxic effects, remain unclear ${ }^{20}$. Weekly ECG monitoring with standard dose of MA should be sufficient to safeguard cardiac adverse effects. The present study has limitations as all patients were healthy young males and each patient served as his own cont-rol. Other potential mechanisms leading to toxicity of pentavalent antimonial were not addressed.

\section{ACKNOWLEDGMENTS}

Authors acknowledge contribution of our patients for participation and paramedical staff for taking care of patients.

\section{CONCLUSION}

Early repolarization defects T-wave inversion followed by ST segment deviation were found with standard doses of meglumine antimoniate therapy.

\section{CONFLICT OF INTEREST}

This study has no conflict of interest to be declared by any author.

\section{REFERENCE:}

1. Shakila A, Bilqees FM, Salim A MM. Geographical distribution of cutaneous leishmaniasis and sand flies in Pakistan. Turkiye Parazitol Derg 2006; 30(1): 1-6.

2. Ayaz MM, Nazir MM, Najeeb Ullah, Aqil Z, Akbar A, Zeeshan $\mathrm{M}$, et al. Cutaneous leishmaniasis in the metropolitan city of Multan, Pakistan, a Neglected Tropical Disease. J Med Entomol 2018; 55(4): 1040-42.

3. Maeireles CB, Maia LC, Soares GC, Teodoro IIP, Gadelha MDSV, da Silva CGL, et al. Atypical presentations of cutaneous leishmaniasis: A systematic review. Acta Trop 2017; 172(1): 240-54.

4. Afghan AK, Kassi M, Kasi M, Kasi PM, Ayub A, Kakar N, Marri SM. Clinical manifestations and distribution of cutaneous leishmaniasis in Pakistan. J Trop Med 2011; 2011(1): 359145-48.

5. Aronson NE, Joya CA. Cutaneous leishmaniasis: updates in diagnosis and management. Infect Dis Clin North Am 2019; 33(1): 110-17.

6. Oliveira LF, Schubach AO, Martins MM, Passos SL, Oliveira RV, Marzochi MC, et al. Systematic review of the adverse effects of cutaneous leishmaniasis treatment in the New World. Acta Trop 2011; 118(2): 87-96.

7. Ashok P, Lathiya $H$, Murugesan S. Manzamine alkaloids as antileishmanial agents: A review. Eur J Med Chem 2015; 5(97): 928-36.

8. Eiras DP, Kirkman LA, Murray HW. Cutaneous leishmaniasis : Current treatment practices in the USA for returning travelers. Curr Treat Options Infect Dis 2015; 7(1): 52-62.

9. Layegh P, Khademi Z, Afzal AM. Systemic meglu-mine antimoniate in cutaneous leishmaniasis of children: clinical and laboratory complications. J Pediat Inf Dis Soc 2015; 4(4): 356-58.

10. Siddique MAB, Hossain MI. ECG Changes in patients of visceral leishmaniasis (Kala-Azar) receiving sodium stibogluconate therapy. Faridpur Med Coll J 2018; 13(2): 70-73.

11. Ejaz A, Raza N, Din Q, Bux H. Outbreak of cutaneous leishmaniasis in Somniani, Balochistan - implementation of preventive measures for deployed personnel of armed forces. J Pak Assoc Dermatol 2008; 18(4): 220-25.

12. De Vries, HJC, Reedijk SH, Schallig HDFH. Cutaneous leishmaniasis: recent developments in diagnosis and management. Am J Clin Dermatol 2015; 16(2): 99-109.

13. Moein D, Masoud D, Saeed M, Abbas M. Epidemiological aspects of cutaneous leishmaniasis during 2009-2016 in Kashan City, Central Iran. Korean J Paras 2018; 56(1): 21-24.

14. Travi BL,Osorio Y, Melby PC, Chandrasekar B, Arteaga L, Saravia NG. Infect Immun. 2002; 70(5): 2288-96.

15. Kevric I, Cappel MA, Keeling JH. New World and old world leishmania infections a practical review. Dermatol Clin 2015; 33(3): 579-93.

16. Shanehsaz SMIS. Electrocardiographic and biochemical adverse effects of meglumine antimoniate (MA) during treatment of Syrian cutaneous leishmaniasis patients. J Pak Assoc Dermatol 2013; 23(4): 412-17. 
17. Sadeghian G, Ziaei H, Sadeghi M. Electrocardiographic changes in patients with cutaneous leishmaniasis treated with systemic glucantime. Ann Acad Med Singap 2008; 37(11): 916-18.

18. Viguer CMT, Errazti E, Soriano FR, Esteban EE, Fernandez FA, Estelles GC. Torsades de pointes during treatment of leishmaniasis with meglumine antimoniate. Rev Esp Cardiol 1999; 52(7): 533-35.
19. Ali A, Butt N, Sheikh AS. Early repolarization syndrome A cause of sudden cardiac death. World J Cardiol 2015; 7(8): 466-75.

20. Moreira VR, de Jesus LCL, Soares RP, Silva LDM, Pinto BAS, Melo MN, et al. Meglumine Antimoniate (Glucantime) Causes Oxidative stress-derived dna damage in Balb/c mice infected by leishmania (leishmania) infantum. Antimicrob Agents Chemother 2017; 61(6): e02360-66. 